\title{
Evaluation of Closed Adult Nucleus Multiple Ovulation and Embryo Transfer and Conventional Progeny Testing Breeding Schemes for Milk Production in Tropical Crossbred Cattle
}

\author{
I. S. Kosgey, ${ }^{1,2}$ A. K. Kahi, ${ }^{2,3}$ and J. A. M. Van Arendonk ${ }^{1}$ \\ ${ }^{1}$ Animal Breeding and Genetics Group, Wageningen University, PO Box 338 \\ $6700 \mathrm{AH}$ Wageningen, The Netherlands \\ ${ }^{2}$ Department of Animal Sciences, Egerton University, PO Box 536, 20107 Njoro, Kenya \\ ${ }^{3}$ Laboratory of Animal Husbandry Resources, Division of Applied Biosciences, \\ Graduate School of Agriculture, Kyoto University, Kyoto, Japan
}

\begin{abstract}
The potential benefits of closed adult nucleus multiple ovulation and embryo transfer (MOET) and conventional progeny testing (CNS) schemes, and the logistics of their integration into large-scale continuous production of crossbred cattle were studied by deterministic simulation. The latter was based on $\mathrm{F}_{1}$ (Bos taurus $\times$ Bos indicus) production using $\mathrm{AI}$ or natural mating and MOET, and continuous $\mathrm{F}_{2}$ production by mating of $\mathrm{F}_{1}$ animals. The gene flow and the cumulative discounted expressions (CDES) were also calculated. Both schemes had 8, 16,32 , or 64 dams with $2,4,8,16$, or 32 sires selected. In the MOET nucleus scheme (MNS), the test capacity was $1,2,8$, or 16 offspring, and the number of matings per dam per year was 1,2 , or 4 . A scheme of 8 sires with 64 dams and a test capacity of 4 female offspring per dam per year resulted in an annual genetic gain (in phenotypic standard deviation) of 0.324 and 0.081 for MNS and CNS, respectively. In the MNS, there was substantial genetic gain with a relatively small number of animals compared with a CNS. The $\mathrm{F}_{1}$ had the highest, and the $\mathrm{F}_{2}$ scheme the lowest CDES. However, a very large number of $B$. indicus females would be required in the $\mathrm{F}_{1}$ scheme. This scheme may not be practical under conditions in developing countries. The $\mathrm{F}_{2}$ scheme was logistically attractive because it produces its own replacements, and the number of $B$. taurus females required would be easy to attain. Accompanying technical and financial constraints of nucleus schemes should be addressed before applying them.
\end{abstract}

(Key words: crossbreeding, dairy cattle, breeding scheme, tropics)

Abbreviation key: CDES = cumulative discounted expressions, CDR = cumulative discounted revenues,

Received February 19, 2004.

Accepted September 2, 2004.

Corresponding author: J. A. M. Van Arendonk; e-mail: johan. vanarendonk@wur.nl.
CNS = conventional nucleus scheme with progeny testing, DD = dams to breed dams selection pathway, $\mathbf{D S}=$ dams to breed sires selection pathway, MNS $=$ MOET nucleus scheme, MOET $=$ multiple ovulation and embryo transfer, $\mathbf{P T}=$ progeny testing, $\mathbf{S D}=$ sires to breed dams selection pathway, $\mathbf{S S}=$ sires to breed sires selection pathway.

\section{INTRODUCTION}

In the tropics, cows need at least some degree of tolerance to environmental stress due to poor nutrition, heat, and disease challenge to sustain relatively high production levels (Cunningham, 1989). Local tropical breeds are adapted to these stressors but have low milk yield, whereas higher productive temperate breeds cannot withstand the harsh tropical conditions, to the point of not being able to sustain their numbers (de Vaccaro, 1990). In view of this, a number of studies have been conducted on crosses between imported (Bos taurus) and adapted Zebu (Bos indicus) breeds. One of the features of these studies has been the superior performance of the $\mathrm{F}_{1} B$. taurus $\times B$. indicus crosses over purebreds (Cunningham and Syrstad, 1987). The heterosis effect of the $F_{1}$ cross is very large and is beneficial for disease resistance (Smith, 1988; Cunningham, 1989). Based on research conducted in Brazil, Madalena (1993) presented an $\mathrm{F}_{1}$ continuous replacement scheme to capitalize on its superiority. The economics of $F_{1}$ females over those from continuous purebreeding or crossbreeding systems with estimates of the break-even cost of producing $\mathrm{F}_{1}$ females have been explored by Teodoro et al. (1996). They did not, however, look at the logistical aspects of the different schemes, especially the size of the purebred indigenous female population required for continuous production of $F_{1}$ animals. Therefore, a feasible and sustainable crossbreeding program for continuous production of crossbred $50 \%$ B. taurus: $50 \%$ B. indicus genotype is required.

In many developing countries, there is no systematic large-scale milk and pedigree recording. The main prob- 
Table 1. Information sources and numbers of observations considered in calculation of selection indices for the multiple-ovulation embryo transfer (MOET) nucleus scheme (MNS) and the conventional progeny testing scheme (CNS).

\begin{tabular}{|c|c|c|c|}
\hline & \multirow{2}{*}{$\frac{\mathrm{MNS}^{1}}{3 \mathrm{yr}}$} & \multicolumn{2}{|c|}{$\mathrm{CNS}^{1}$} \\
\hline & & $3.5 \mathrm{yr}$ & $6.5 \mathrm{yr}$ \\
\hline \multicolumn{4}{|l|}{ Males } \\
\hline Progeny & $(-)$ & $(-)$ & $(+)$ \\
\hline Full-sibs & $\left(\mathrm{m}_{\mathrm{tot}} / \mathrm{m}_{\mathrm{d}}\right) \times \mathrm{n}_{\mathrm{f}}$ & & \\
\hline Paternal half-sibs & $\mathrm{m}_{\mathrm{tot}} \times \mathrm{n}_{\mathrm{f}}\left(\mathrm{n}_{\mathrm{d}} / \mathrm{n}_{\mathrm{s}}-1 / \mathrm{m}_{\mathrm{d}}\right)$ & $\mathrm{n}_{\mathrm{d}} \times \mathrm{m}_{\mathrm{d}} \times \mathrm{p}_{\mathrm{f}} / \mathrm{n}_{\mathrm{s}}$ & $\mathrm{n}_{\mathrm{d}} \times \mathrm{m}_{\mathrm{d}} \times \mathrm{p}_{\mathrm{f}} / \mathrm{n}_{\mathrm{s}}$ \\
\hline Maternal half-sibs & $\mathrm{m}_{\mathrm{tot}} \times \mathrm{n}_{\mathrm{f}}\left(1-1 / \mathrm{m}_{\mathrm{d}}\right)$ & & \\
\hline \multicolumn{4}{|l|}{ Nucleus cows } \\
\hline Dam phenotype & 1 & & \\
\hline Own performance & 1 & & \\
\hline Full sibs & {$\left[\left(\mathrm{m}_{\mathrm{tot}} / \mathrm{m}_{\mathrm{d}}\right) \times \mathrm{n}_{\mathrm{f}}\right]-1$} & & \\
\hline Paternal half-sibs & $\mathrm{m}_{\mathrm{tot}} \times \mathrm{n}_{\mathrm{f}}\left(\mathrm{n}_{\mathrm{d}} / \mathrm{n}_{\mathrm{s}}-1 / \mathrm{m}_{\mathrm{d}}\right)$ & & \\
\hline Maternal half-sibs & $\mathrm{m}_{\mathrm{tot}} \times \mathrm{n}_{\mathrm{f}}\left(1-1 / \mathrm{m}_{\mathrm{d}}\right)$ & & \\
\hline
\end{tabular}

lems in setting up and running milk and pedigree recording schemes in these countries have been reported by Lindström (1976). Nicholas and Smith (1983) proposed the use of multiple ovulation and embryo transfer (MOET) nucleus schemes to increase the rate of genetic gain in dairy cattle breeding. The models they used assumed the establishment of a central herd ("a nucleus") and all selection being based on recordings obtained from that herd. The emerging dairy subsectors in tropical developing countries need to consider use of new animal breeding technologies (Hodges, 1990; Seidel and Seidel, 1992). The MOET nucleus schemes (MNS) are of considerable relevance to developing countries, especially where progeny testing (PT) schemes are not feasible and where suitable semen cannot be imported (McGuirk, 1992; Seidel and Seidel, 1992). However, the enormous logistical and resource challenges facing nucleus breeding schemes in tropical developing countries are critically important issues on which policy and decision makers require advice. In countries with a well-functioning conventional breeding scheme based on field testing of AI bulls, "mixed" or "hybrid" MOET schemes have been developed where selection of males on field progeny tests is combined with superovulation and embryo transfer in a nucleus where selection of females is practiced (de Boer and van Arendonk, 1994; Callesen et al., 1996). Closed MNS and PT schemes have been studied by Mpofu et al. (1993) in Zimbabwe. In Kenya, Kahi et al. (2000b) evaluated a 2-tier open nucleus breeding scheme utilizing untested young bulls for milk production from purebred dairy cattle. However, the integration of nucleus schemes into dairy cattle crossbreeding systems in the tropics was not examined in detail in the previous studies.
The aim of the current study was to examine the potential benefits of MOET and conventional breeding with PT in a closed adult nucleus scheme in terms of annual genetic gain, using different numbers of sires, test capacities, and matings. Logistics of integration of the nucleus scheme into large-scale continuous production of crossbred cattle were studied based on $\mathrm{F}_{1}(50 \%$ B. taurus: $50 \%$ $B$. indicus) production through the use of $\mathrm{AI}$ or natural mating and MOET and $\mathrm{F}_{2}(50 \%$ B. taurus: $50 \%$ B. indicus) production by inter se matings. The ultimate aim was to optimize a breeding program using MOET as an option for increasing the genetic merit of production traits in dairy cattle in the tropics.

\section{MATERIALS AND METHODS}

Deterministic simulation was used to assess the annual genetic gains of 2 dairy cattle breeding schemes: MNS and a conventional nucleus scheme with progeny testing (CNS). The breeding goal was to improve milk yield in first lactation, which commenced at 33 mo of age and had a heritability of 0.23 and repeatability of 0.4 (Verneque et al., 1987). In the tropics, adaptability to harsh conditions such as diseases, heat stress, and poor nutrition is important. Using a balanced 50:50 B. taurus: $B$. indicus genotype in a stressful environment implicitly implies improving both milk yield and adaptation (Franklin, 1986). In this study, no adjustments were made for reduction of genetic variance due to selection and inbreeding and reduction of selection differentials due to the small number of selection candidates. As a consequence, the obtained genetic gains are to be considered as upper bounds, which will serve to rank the schemes. The simulation assumed that the base popula- 


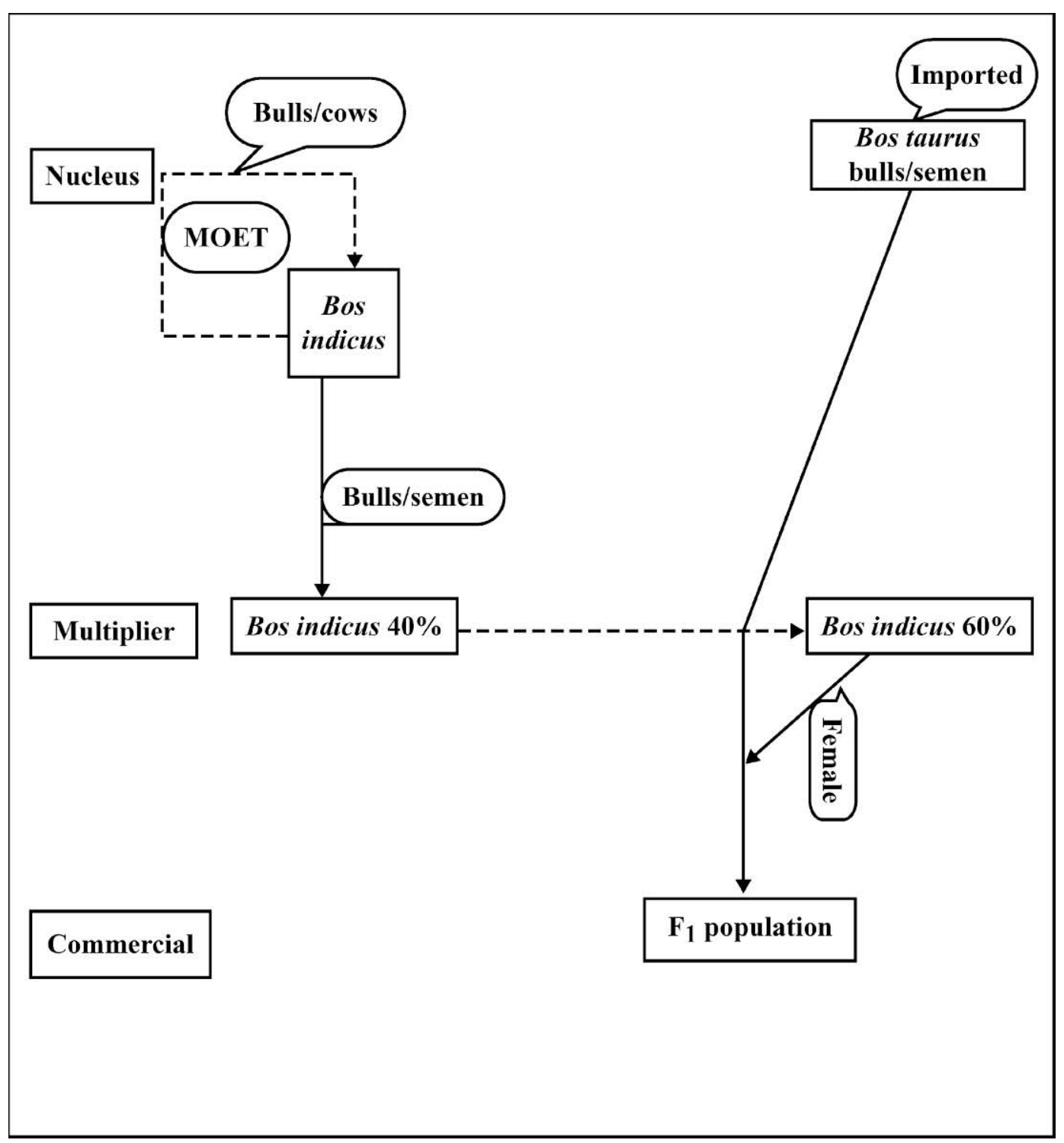

Figure 1. Continuous multiple-ovulation embryo transfer (MOET) $\mathrm{F}_{1}$ production scheme.

tion was unselected. The effects of varying test capacities, numbers of matings and sires were investigated in the MNS. For CNS, the effects of test capacity and number of matings could not be investigated due to the limited reproductive capacity of females in this scheme (Kosgey, 1997). In MNS, the effect of $8,16,32$, and 64 dams and a varying number of selected sires were studied for schemes with $32,64,128$, and 256 cows, respectively. The test capacities were $1,2,8$, and 16 offspring whereas the numbers of matings were 1,2 , and 4 per dam per year. In CNS, 12 daughters were recorded per sire, which corresponds to 104, 208, 416, and 832 offspring. Table 1 shows the information sources and the numbers of observations considered in the calculation of selection indices for both schemes.

\section{Characteristics of the Simulated Breeding Schemes}

MOET nucleus schemes. An adult MNS was considered (Figures 1 and 2). The base schemes comprised 8 sires and 8, 16,32, or 64 dams that produced 4 offspring per dam per MOET session, i.e., 2 males and 2 females. There were 2 MOET sessions with the same sire per dam each year. A maximum of 1 male was randomly selected from a full-sib family to be used for breeding. In the nucleus, every dam was mated to at least 1 sire. All 4 females in a full-sib family in the MNS were tested, and the top-ranking females across all families were selected for breeding the next generation. These females were selected based on their performance in the initial 3 mo of their first lactation and on information from 


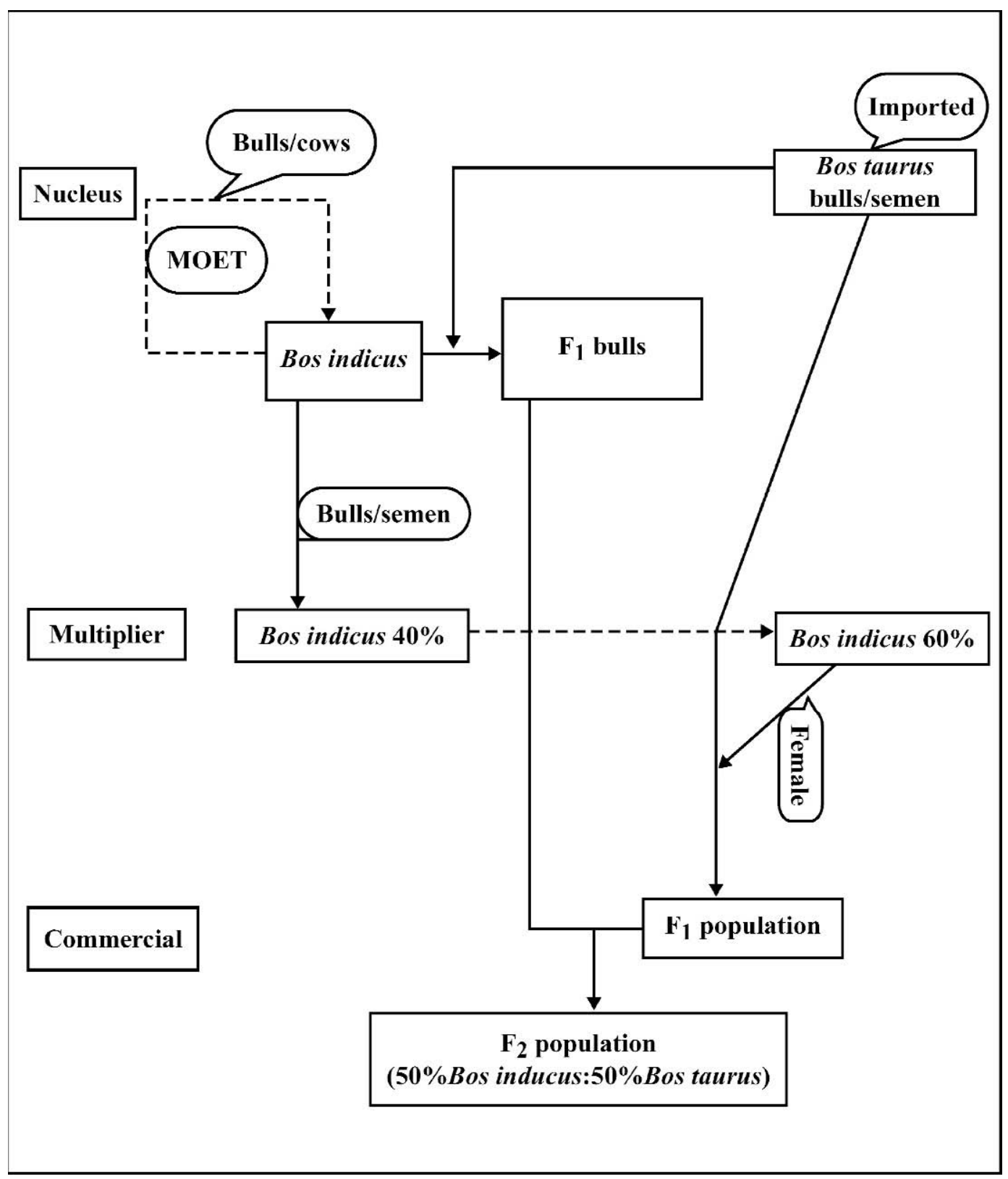

Figure 2. Continuous crossbred production scheme $\left(\mathrm{F}_{2}\right.$ inter se).

relatives. This meant that females were eligible for selection at $3 \mathrm{yr}$ of age. Males were selected at the same age using information from full- and half-sibs.

Conventional progeny-testing schemes. This scheme selected males based on information from their paternal half-sibs and progeny. No superovulation and embryo transfer was used (Figure 3). The scheme allowed for 2 calvings per generation and a $50 \%$ sex ratio. The base schemes had 8 sires and 8,16,32, or 64 dams with 2 matings per generation. Males were eligible for selection at 3.5 and $6.5 \mathrm{yr}$ of age (Table 1 ). Females were mated using AI or natural mating at an average age of $3.5 \mathrm{yr}$, because some females were born from the first and second matings. Dams were assigned equally to sires. Males undergoing PT in this scheme therefore had records of daughters available at an average of $6.5 \mathrm{yr}$. There was no selection of dams in this scheme.

\section{Annual Genetic Gains}

The effectiveness of the breeding schemes was assessed by comparing their predicted genetic gains. 


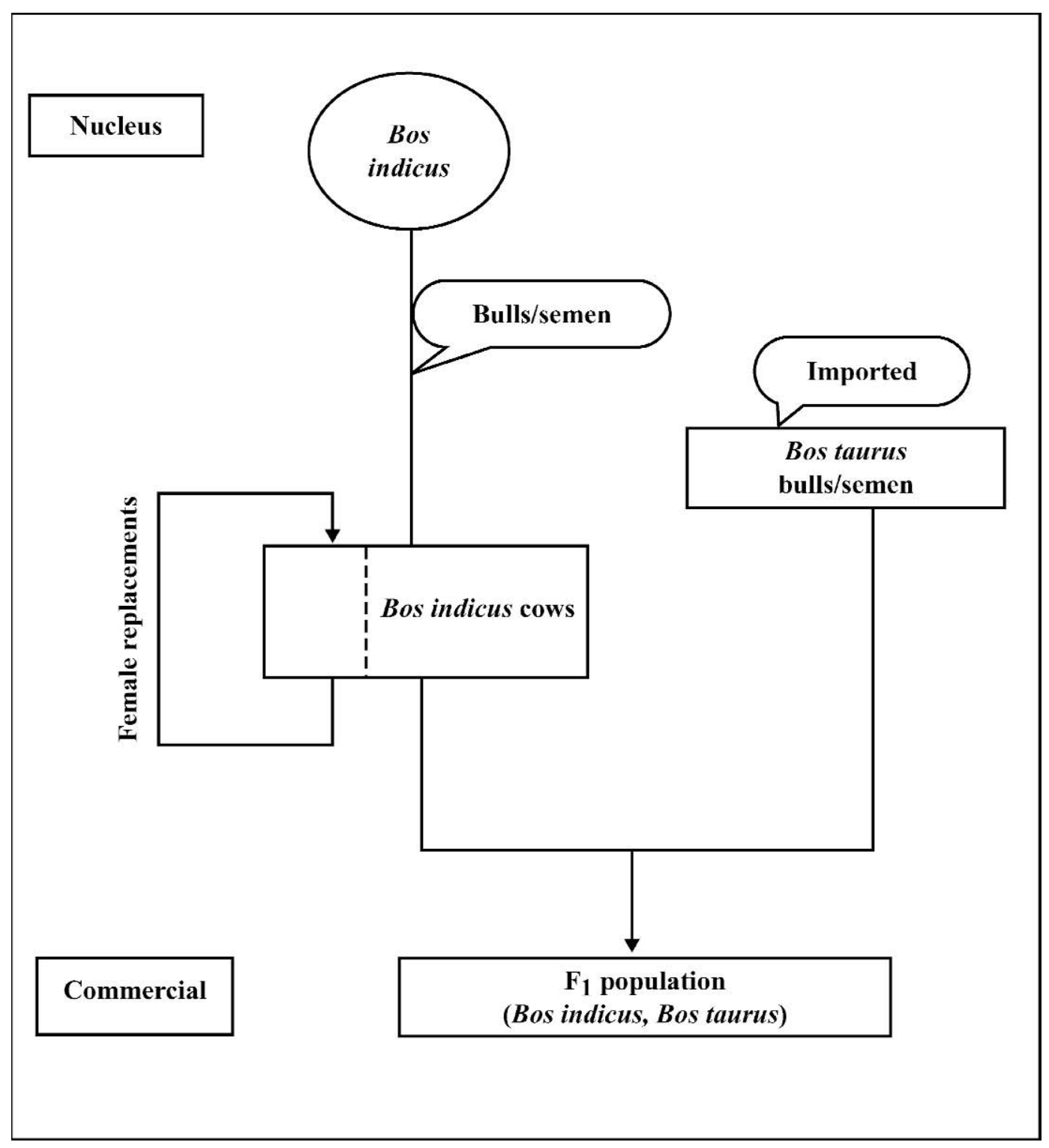

Figure 3. Artificial insemination or natural mating $\mathrm{F}_{1}$ production scheme.

Therefore, standard deviations of breeding goal, aggregate genotype, accuracies of selection, and selection intensities were calculated using selection index theory (Hazel, 1943). The selection pathways considered were sires to breed sires (SS), sires to breed dams (SD), dams to breed sires (DS), and dams to breed dams (DD). The estimate of annual genetic gain was calculated using the Rendel and Robertson (1950) formula:

$$
\Delta G=\frac{\sum_{l=1}^{L}\left(i \times r_{I H} \times \sigma_{H}\right)_{l}}{\sum_{l=1}^{L} L_{l}}
$$

where $\Delta \mathrm{G}$ is the predicted genetic gain per year summed over all selection pathways, $\mathrm{i}$ is the selection intensity, $\mathrm{r}_{\mathrm{IH}}$ is the accuracy of selection, $\sigma_{\mathrm{H}}$ is the genetic standard deviation, and $\sum_{l=1}^{L} L_{l}$ is the summation of generation intervals in the $l$ th selection pathway.

\section{Integration Logistics}

Production schemes and breeding plan. Logistics of integration of the nucleus scheme into largescale continuous production of crossbred cattle were studied. These were based on 3 production schemes: 
$\mathrm{F}_{1}(50 \%$ B. taurus: $50 \%$ B. indicus) MOET scheme (Figure 1$) ; \mathrm{F}_{2}(50 \%$ B. taurus $50 \%$ B. indicus $)$ scheme by inter se matings (Figure 2), and $\mathrm{F}_{1}$ (50\%B. taurus: $50 \%$. indicus) scheme through use of AI or natural mating (Figure 3). The schemes involve genetically improved purebred local $B$. indicus animals and imported semen from B. taurus males (e.g., Friesian, Ayrshire, or Brown Swiss). Absence of significant differences in the additive breed effects of the B. taurus breeds for profitability has been reported in Kenya (Kahi et al., 2000a). The $\mathrm{F}_{1}$ AI or natural mating scheme assumed 2 tiers, namely the nucleus and the commercial population, whereas the other 2 schemes included a multiplier tier in which replacement heifers were bred for the production of $\mathrm{F}_{1}$ to be disseminated to the commercial population. In the $\mathrm{F}_{1} \mathrm{AI}$ or natural mating scheme, the nucleus generated the $F_{1}$ females and the purebred $B$. indicus males and females. These $\mathrm{F}_{1}$ females were disseminated to the commercial population and the purebred $B$. indicus males and females were used within the nucleus to maintain the $B$. ind $i$ cus breed.

In the MOET $F_{1}$ scheme, the nucleus generated, through MOET, the purebred $B$. indicus males and females, which were used within the nucleus and in the multiplier tier to further breed purebred $B$. indicus. Within the multiplier tier, only $40 \%$ of the purebred $B$. indicus females were bred with $B$. indicus males, whereas the remainder was used for crossbreeding with $B$. taurus males to produce $\mathrm{F}_{1}$ females, which were disseminated to the commercial population. The breeding strategy for the continuous $\mathrm{F}_{2}$ production scheme was as described above for the MOET $\mathrm{F}_{1}$ scheme. However, $\mathrm{F}_{1}$ males were also generated in the nucleus, and they were used in the $\mathrm{F}_{1}$ commercial population existing once the program was operational, to produce an $\mathrm{F}_{2}$ population with equal gene proportions from the $B$. taurus and the $B$. indicus breeds. Very few crossbreeding projects have thus far included production of $\mathrm{F}_{2}$ in their designs, an observation also made by Syrstad (1989). In all the schemes, genetic progress was made in the nucleus through selection of sires based on information from fullsibs and half-sibs and performance of dams.

Animal numbers. The number of sires and dams required to run the above mentioned schemes were calculated for production of 1000 of either $F_{1}$ or $F_{2}$ firstcalving heifers. To determine the number of dams, the following parameters were assumed. The average number of calvings per cow per lifetime $(\mathrm{AC})=5$, calving interval $(\mathrm{CI})=1.2 \mathrm{yr}$, and the average stage of lactation (in yr) when culled (SC) $=0.4$ (Kosgey, 1997). Average herd life was expressed as $(\mathrm{AC}-1) \times \mathrm{CI}+\mathrm{SC}$. The annual replacement rate is equivalent to the reciprocal of the average herd life if the herd size is in equilibrium. In the example, it was 0.2 . The calving rate defined as the number of calves per animal in the herd, excluding young stock, was calculated as $\mathrm{AC} /[(\mathrm{AC}-1) \times \mathrm{CI}+\mathrm{SC}]$. A survival rate up to first calving of 0.70 , calving rate of 0.96 , a sex ratio of 0.5 , and a replacement rate of 0.20 were assumed. The number of heifer calves that should be born (dead or alive) is given by: $1000 \times 1$ /survival rate. This includes deaths at birth and up to first calving.

To calculate the number of sires required, a population of 500,000 cows was assumed for purposes of illustration. In case of AI, 2 inseminations per pregnancy were assumed and for natural matings, a bull was assumed to service 100 cows per year. The number of sires required when both $\mathrm{AI}$ and natural mating $\left(\mathrm{F}_{2}\right.$ inter se) are used in combination was derived in a similar way.

Gene flow. The gene flow procedures of Hill (1974) using matrix formulation as described by Brascamp (1978) were used to examine the flow of genes to the commercial population and the cumulative discounted revenues (CDR) for the crossbreeding schemes. Gene flow represents the proportion of genes in a group of animals originating from a base population (Hill, 1974), or the proportion of the additive genetic merit of the base population to be expressed in a progeny group (Elsen, 1980). Genes flow in time through the processes of reproduction and aging.

As already alluded to, selection was done only in the nucleus, and it was based on the 4 selection paths: SS, $\mathrm{SD}, \mathrm{DS}$, and DD. The evaluation criterion was milk yield measured in age classes 3 through 10 in the $F_{1}$ and $F_{2}$ commercial cow populations. The economic value of milk was US\$ 0.25 per kg/cow (Kahi and Nitter, 2004). The schemes were evaluated over a 30 -yr projected period with assumed interest rates of 0 and $10 \%$ per annum. The 0\% interest rate shows the genetic level. The following gene flow model as described by Brascamp (1978) was used:

$$
\mathrm{m}_{\mathrm{t}}=(\mathrm{R}+\mathrm{Q}) \mathrm{m}_{\mathrm{t}-1}=\mathrm{PM}_{\mathrm{t}-1}
$$

where $m_{t}$ is the proportion of genes at time $t, R$ is the proportion of genes in an age class obtained from the age class from one time period earlier through reproduction, $\mathrm{Q}$ is the flow of genes through aging, and $\mathrm{P}$ is a matrix with summation of $R$ and $Q$ elements. The $P$ matrix specifies the contribution of different age classes to the next generation and is different for each of the schemes, i.e., the contributions of the different age classes to the next generation are not the same across years. A period of $1 \mathrm{yr}$ was used.

As indicated, 2 schemes $\left(\mathrm{F}_{1}\right.$ MOET and $\mathrm{F}_{1} \mathrm{AI}$ or natural mating) were distinguished for continuous $\mathrm{F}_{1}$ production (Figures 1 and 3), whereas in the continuous $\mathrm{F}_{2}$ production there was only one scheme based on MOET 
and mating in the commercial population was inter se (Figure 2). In this $\mathrm{F}_{2}$ scheme, nucleus males had progeny in the nucleus in age class 4 only, but they were also used in the multiplier herd in age classes 4, 5, and 6 with distribution in age classes of 50,30, and $20 \%$, respectively. Nucleus females produced nucleus progeny when they were in the third age class only, and were further used up to age class 10 with a distribution of $20 \%$ in classes 4 and 5, 15\% in classes 6 and 7, and $10 \%$ in the remaining classes. Multiplier B. indicus females had progeny when they were in age classes 3 to 10 with distribution of $20 \%$ in class $6,15 \%$ in classes 7 and 8 , and $10 \%$ in each of the remaining classes. The $\mathrm{F}_{1}$ males had progeny in classes 2 to 6 with a distribution that ranged from 30\% for age class 2 to $10 \%$ for age class 6 with a $5 \%$ difference between the consecutive classes. Both $\mathrm{F}_{1}$ and $\mathrm{F}_{2}$ commercial females had progeny from age classes 3 to 10 . The age distribution was $20 \%$ for age class $5,15 \%$ for age classes 6 and 7 , and $10 \%$ for each of the remaining age classes. However, in the commercial population, only $20 \%$ of the females were $\mathrm{F}_{1}$ and $80 \%$ were inter se females.

In the $\mathrm{F}_{1} \mathrm{AI}$ or natural mating scheme, the age classes and contributions for the males and females were similar to those in the $F_{2}$ production scheme for the $F_{1}$ males and commercial females, respectively. However, only $\mathrm{F}_{1}$ commercial females were used for production. In the $\mathrm{F}_{1}$ MOET scheme, apart from the absence of the $\mathrm{F}_{2}$ commercial tier and $100 \%$ of $\mathrm{F}_{1}$ females being used for production, the age distributions at the time offspring were born were the same as described above for the $\mathrm{F}_{2}$ scheme.

Total discounted financial response per commercial cow to one cycle of selection was calculated as:

$$
\sum_{1} \mathrm{i} \times \mathrm{r}_{\mathrm{IH}} \times \sigma_{\mathrm{H}} \times \mathrm{CDES} \times \mathrm{v}
$$

where i, $\mathbf{r}_{\mathrm{IH}}$, and $\sigma_{\mathrm{H}}$ are as described in equation [1], CDES is the cumulative discounted expressions, and v is the economic value of milk yield. Using a $20 \% \mathrm{CV}$, a mean lactation milk yield of $2500 \mathrm{~kg}$ (Kosgey, 1997) and a heritability of 0.23 (Verneque et al., 1987) results in $\sigma_{\mathrm{H}}=240$. The CDR were also calculated for these schemes. The CDES of a trait reflects time and frequency of future expression of superior genotype originating from a selected individual (Brascamp, 1978) and differs between selection paths (Groen, 1990). The genetic difference between the indigenous nucleus animals, the $\mathrm{F}_{1}$ males, and the commercial female population was calculated by defining the incidence vector as the difference between the 3 groups.

\section{RESULTS}

\section{MOET Nucleus Schemes}

Number of sires. Table 2 presents the results of MNS with $8,16,32$, and 64 dams, and a varying number of sires. The scheme with 8 selected sires was used as a base in comparisons. Genetic gains are expressed in units of phenotypic standard deviation $\left(\sigma_{\mathrm{p}}\right)$.

Increase in the number of selected sires had a negative impact on annual genetic gain. For example, in the scheme with 64 dams, selection of 32 sires reduced the annual genetic gain by 0.091 relative to the base scheme (Table 2). Conversely, selection of 2 sires gave a gain of 0.07 over the base scheme. This was largely due to differences in selection intensities of sires and accuracies of selection. In general, the fewer the number of sires that were selected, the higher the selection intensities (Table 2). A notably higher selection intensity was apparent with selection of 2 sires in the scheme with 64 dams. Selection intensity for dams was constant and unaffected by the number of sires selected across the schemes.

The accuracy of selection for both sires and dams decreased with increasing number of sires selected. For example, in the scheme with 64 dams, selection of 32 sires resulted in 0.03 and 0.06 units lower accuracies of selection for dams and sires, respectively, compared with the base scheme (Table 2). In contrast, in the 32-dam scheme, dams had 0.03 and 0.02 units higher accuracy of selection relative to the base situation with 2 and 4 selected sires, respectively. The number of relatives that provided information for breeding value estimation decreased when more sires were chosen and vice versa.

The scheme with 16 dams had a shortage of candidate bulls when 32 sires were to be selected. In this scheme, all the bulls were used as replacements already when 16 sires were selected, so there was no selection. This also applied to the selection of 32 sires in the 32-dam scheme, and selection of more than 8 sires in the 8-dam scheme. In these schemes, there was a maximum of one sire selected out of each full-sib family.

Number of offspring (test capacity) or matings. Increase in test capacity increased the annual genetic gain (Table 3). For instance, in the scheme with 64 dams, genetic gain increased from 0.102 to 0.477 when the number of tested offspring was increased from 1 to 16 . The increased selection intensities of dams and the increased accuracies of selection for both sires and dams contributed to this increased annual genetic gain. In all schemes, the selection intensity of sires was the same and remained unaffected by the number of offspring.

The selection intensity of dams was zero with 1 offspring per dam per year. This was because there was a maximum of 1 selected offspring out of each full-sib family. The selection intensity increased to 1.967 for 16 
Table 2. The effect of the number of selected sires when the number of dams is varied for the multipleovulation embryo transfer (MOET) nucleus scheme (MNS).

\begin{tabular}{|c|c|c|c|c|c|c|c|c|}
\hline \multirow{2}{*}{$\begin{array}{l}\text { Dams } \\
\text { selected }\end{array}$} & \multirow{2}{*}{$\begin{array}{l}\text { Sires } \\
\text { selected }^{1}\end{array}$} & \multirow{2}{*}{$\begin{array}{l}\text { Cows } \\
\text { tested }\end{array}$} & \multicolumn{2}{|c|}{$\mathrm{Dams}^{2}$} & \multicolumn{2}{|c|}{ Sires $^{2}$} & \multirow[b]{2}{*}{$\mathrm{G}\left(\sigma_{\mathrm{p}}\right)^{3}$} & \multirow[b]{2}{*}{$\mathrm{F}^{4}$} \\
\hline & & & $\mathrm{r}_{\mathrm{IH}}$ & $\mathrm{i}$ & $\mathrm{r}_{\mathrm{IH}}$ & $\mathrm{i}$ & & \\
\hline \multicolumn{9}{|l|}{64} \\
\hline & 2 & 256 & 0.64 & 1.271 & 0.54 & 2.251 & 0.394 & 0.064 \\
\hline & 4 & 256 & 0.63 & 1.271 & 0.53 & 1.967 & 0.361 & 0.033 \\
\hline & 8 & 256 & 0.62 & 1.271 & 0.51 & 1.647 & 0.324 & 0.018 \\
\hline & 16 & 256 & 0.60 & 1.271 & 0.48 & 1.271 & 0.279 & 0.010 \\
\hline & 32 & 256 & 0.59 & 1.271 & 0.45 & 0.798 & 0.233 & 0.006 \\
\hline \multicolumn{9}{|l|}{32} \\
\hline & 2 & 128 & 0.63 & 1.271 & 0.53 & 1.967 & 0.361 & 0.066 \\
\hline & 4 & 128 & 0.62 & 1.271 & 0.51 & 1.647 & 0.324 & 0.035 \\
\hline & 8 & 128 & 0.60 & 1.271 & 0.48 & 1.271 & 0.279 & 0.020 \\
\hline & 16 & 128 & 0.59 & 1.271 & 0.45 & 0.798 & 0.233 & 0.012 \\
\hline & 32 & 128 & 0.58 & 1.271 & 0.43 & 0.000 & 0.168 & 0.008 \\
\hline 16 & 2 & 64 & 0.62 & 1.271 & 0.51 & 1.647 & 0.324 & 0.070 \\
\hline & 4 & 64 & 0.60 & 1.271 & 0.48 & 1.271 & 0.279 & 0.039 \\
\hline & 8 & 64 & 0.59 & 1.271 & 0.45 & 0.798 & 0.233 & 0.023 \\
\hline & 16 & 64 & 0.58 & 1.271 & 0.43 & 0.000 & 0.168 & 0.016 \\
\hline \multirow{2}{*}{\multicolumn{9}{|c|}{8}} \\
\hline & & & & & & & & \\
\hline & 4 & 32 & 0.59 & 1.271 & 0.45 & 0.798 & 0.233 & 0.047 \\
\hline & 8 & 32 & 0.58 & 1.271 & 0.43 & 0.000 & 0.168 & 0.031 \\
\hline & 16 & 32 & 0.58 & 1.271 & 0.43 & 0.000 & 0.168 & 0.023 \\
\hline & 32 & 32 & 0.58 & 1.271 & 0.43 & 0.000 & 0.168 & 0.020 \\
\hline
\end{tabular}

${ }^{1}$ The base schemes are those with 8 sires selected.

${ }^{2} \mathrm{r}_{\mathrm{IH}}=$ Accuracy of selection, $\mathrm{i}$ = selection intensity; $\mathrm{r}_{\mathrm{IH}}$ and $\mathrm{i}$ were different for dams and sires.

${ }^{3} \mathrm{G}=$ Rate of genetic gain measured in phenotypic standard deviations $\left(\sigma_{\mathrm{p}}\right)$.

${ }^{4} \mathrm{~F}=$ Rate of inbreeding.

tested female offspring per dam per year in all schemes. It was clear that a higher test capacity provided more female candidates, and therefore enabled more intense selection of dams.

The effect of the number of matings per cow with 8 sires and varying number of dams for the MNS is shown in Table 4 . When the effect of test capacity (Table 3) and number of matings (Table 4) on genetic gain are compared, it can clearly be seen that 1 vs. 4 matings generally had the same effect as a test capacity of $2 \mathrm{vs}$. 8 offspring per dam per year, respectively.

\section{Conventional Progeny-Testing Scheme}

As indicated earlier, the effects of test capacity and number of matings could not be investigated for this scheme due to the limited reproductive capacity of females. Table 5 shows the effect of number of sires on genetic gain in situations with 16, 32, and 64 dams. Dams were not selected because there could only be one dam per full-sib family. The scheme with 8 selected sires was used as a base in making comparisons.

The annual genetic gains were higher for selection of sires at $3.5 \mathrm{yr}$ of age compared with $6.5 \mathrm{yr}$ of age in most cases. For instance, the scheme with 64 dams and selection of 2 sires resulted in 0.07 higher annual genetic gain when selection was at $3.5 \mathrm{yr}$ of age compared with selection at $6.5 \mathrm{yr}$ of age (Table 5). Although there was an advantage of using progeny information at the later selection age, and hence higher accuracy of selection, this was more than offset by the reduced generation interval when selection was at $3.5 \mathrm{yr}$.

Selection of fewer sires resulted in more annual genetic gain compared with selection of more sires and vice versa. This was primarily due to selection intensity and accuracy of selection. The selection intensity of sires increased when the number of selected sires in the scheme decreased. The accuracy of selection also increased with selection of fewer sires. For instance, in the scheme with 64 dams and selection of sires at $3.5 \mathrm{yr}$ of age, the accuracies of selection for 2 and 4 sires were, correspondingly, 0.12 and 0.06 units higher relative to the base scheme (Table 5). Conversely, 16 and 32 sires both resulted in accuracies of selection that were 0.01 lower relative to the base scheme. In general, the fewer the number of sires that were selected, the more they benefited from information from more relatives.

\section{Animal Numbers}

If 1000 first-calving $\mathrm{F}_{2}$ heifers are required, then the number of heifer calves that should be born (dead or 
Table 3. The effect of test capacity with 8 selected sires when the number of dams is varied for the multipleovulation embryo transfer (MOET) nucleus scheme (MNS).

\begin{tabular}{|c|c|c|c|c|c|c|c|c|}
\hline \multirow{2}{*}{$\begin{array}{l}\text { Dams } \\
\text { selected }\end{array}$} & \multirow{2}{*}{$\begin{array}{l}\text { Test } \\
\text { capacity }^{1}\end{array}$} & \multirow{2}{*}{$\begin{array}{l}\text { Cows } \\
\text { tested }\end{array}$} & \multicolumn{2}{|c|}{$\operatorname{Dams}^{2}$} & \multicolumn{2}{|c|}{ Sires $^{2}$} & \multirow[b]{2}{*}{$\mathrm{G}\left(\sigma_{\mathrm{p}}\right)^{3}$} & \multirow[b]{2}{*}{$\mathrm{F}^{4}$} \\
\hline & & & $\mathrm{r}_{\mathrm{IH}}$ & $\mathrm{i}$ & $\mathrm{r}_{\mathrm{IH}}$ & $\mathrm{i}$ & & \\
\hline \multicolumn{9}{|l|}{64} \\
\hline & 1 & 32 & 0.57 & 0.000 & 0.36 & 1.647 & 0.102 & 0.018 \\
\hline & 2 & 64 & 0.58 & 0.798 & 0.44 & 1.647 & 0.230 & 0.018 \\
\hline & 4 & 128 & 0.62 & 1.271 & 0.51 & 1.647 & 0.324 & 0.018 \\
\hline & 8 & 128 & 0.65 & 1.647 & 0.56 & 1.647 & 0.402 & 0.018 \\
\hline \multirow{2}{*}{\multicolumn{9}{|c|}{32}} \\
\hline & & & & & & & & \\
\hline & $\begin{array}{l}1 \\
2\end{array}$ & $\begin{array}{r}04 \\
128\end{array}$ & 0.57 & 0.798 & 0.40 & 1.271 & 0.191 & $\begin{array}{l}0.020 \\
0.020\end{array}$ \\
\hline & 4 & 256 & 0.60 & 1.271 & 0.48 & 1.271 & 0.279 & 0.020 \\
\hline & 8 & 512 & 0.65 & 1.647 & 0.55 & 1.271 & 0.364 & 0.020 \\
\hline & 16 & 1024 & 0.68 & 1.967 & 0.61 & 1.271 & 0.438 & 0.020 \\
\hline \multicolumn{9}{|l|}{16} \\
\hline & $\begin{array}{l}1 \\
2\end{array}$ & $\begin{array}{l}16 \\
32\end{array}$ & $\begin{array}{l}0.55 \\
0.55\end{array}$ & $\begin{array}{l}0.000 \\
0.798\end{array}$ & $\begin{array}{l}0.28 \\
0.36\end{array}$ & $\begin{array}{l}0.798 \\
0.798\end{array}$ & $\begin{array}{l}0.038 \\
0.149\end{array}$ & $\begin{array}{l}0.023 \\
0.023\end{array}$ \\
\hline & 4 & 64 & 0.59 & 1.271 & 0.45 & 0.798 & 0.233 & 0.023 \\
\hline & 8 & 128 & 0.64 & 1.647 & 0.53 & 0.798 & 0.313 & 0.023 \\
\hline & 16 & 256 & 0.68 & 1.967 & 0.60 & 0.798 & 0.387 & 0.023 \\
\hline \multicolumn{9}{|l|}{8} \\
\hline & 1 & 8 & 0.55 & 0.000 & 0.28 & 0.000 & 0.000 & 0.031 \\
\hline & 2 & 16 & 0.55 & 0.798 & 0.35 & 0.000 & 0.100 & 0.031 \\
\hline & 4 & 32 & 0.58 & 1.271 & 0.43 & 0.000 & 0.168 & 0.031 \\
\hline & 8 & 64 & 0.63 & 1.647 & 0.51 & 0.000 & 0.237 & 0.031 \\
\hline & 16 & 128 & 0.67 & 1.967 & 0.58 & 0.000 & 0.301 & 0.031 \\
\hline
\end{tabular}

${ }^{1}$ The base schemes are those with a test capacity of 4 .

${ }^{2} \mathbf{r}_{\mathrm{IH}}=$ Accuracy of selection, $\mathrm{i}$ = selection intensity; $\mathrm{r}_{\mathrm{IH}}$ and $\mathrm{i}$ were different for dams and sires.

${ }^{3} \mathrm{G}=$ Rate of genetic gain measured in phenotypic standard deviations $\left(\sigma_{\mathrm{p}}\right)$.

${ }^{4} \mathrm{~F}=$ Rate of inbreeding.

alive) would be 1429 . This includes deaths at birth and up to first calving. The number of $\mathrm{F}_{1}$ dams needed to yield 1000 first-calving $\mathrm{F}_{2}$ heifers under $\mathrm{AI}$ or natural mating would be 2976 . In the same way, $2976 \mathrm{~B}$. indicus (of which $60 \%$ are to be used in crossbreeding) cows would be required to produce the $1000 \mathrm{~F}_{1}$ dams. To maintain the $B$. indicus herd numbers, there is also a yearly requirement of purebred $B$. indicus heifers, which should be obtained from the remaining $40 \%$ of $B$. indicus cows (used in purebreeding). Therefore, the total number of $B$. indicus cows required for both pure- and crossbreeding would be about 4960 . This is a relatively large number of animals to be kept in a nucleus or to be found concentrated in a few herds.

The number of $\mathrm{F}_{1}$ bulls required to run, for example, a scheme of 500,000 cows under AI would be 10 . However, under natural mating, $5000 \mathrm{~F}_{1}$ bulls would be required. This is a high number of animals to attain from a nucleus scheme. The number of dams to produce 5000 bulls per year for natural mating would be 1250 . Under mixed natural mating and AI (50:50), 2505 bulls would be required.

\section{Cumulative Discounted Expressions and Revenues}

In the continuous $\mathrm{F}_{2}$ production scheme, CDES were realized from the 13th year onwards for both SS and DS pathways and from the 14th year for both SD and DD at $0 \%$ interest rates (data not shown). The corresponding times for $\mathrm{F}_{1}$ MOET scheme were 11th year for SS and $\mathrm{DS}$, and 15th year for SD and DD. The $\mathrm{F}_{1} \mathrm{AI}$ or natural mating had CDES realized from the 10th year onwards for both SS and DS and from the seventh year for SD and DD paths for the same interest rate. It is expected that genes from SS and DS paths in the continuous $\mathrm{F}_{2}$ production and $\mathrm{F}_{1}$ MOET schemes will appear earlier than from SD and DD paths, as the sire paths are shorter in gene dissemination. However, the converse is true for AI or natural mating schemes. These results indicate that the $\mathrm{F}_{1} \mathrm{AI}$ or a natural mating scheme is faster in dissemination of genes to the commercial population than the continuous $\mathrm{F}_{2}$ production schemes.

The CDES per commercial cow after one round of selection over a period of $30 \mathrm{yr}$ are shown in Table 6 and the corresponding revenues for a nucleus scheme with 64 dams in Table 7 . At both interest rates, the $\mathrm{F}_{1} \mathrm{AI}$ or natural scheme had the highest and the continuous $\mathrm{F}_{2}$ scheme the lowest CDES. The CDES for the $\mathrm{F}_{1}$ MOET were intermediate. The $\mathrm{F}_{1} \mathrm{AI}$ or natural mating was also superior to the other schemes for CDR for a nucleus with 64 dams (Table 7). The continuous $\mathrm{F}_{2}$ production scheme was intermediate. Therefore, the $\mathrm{F}_{1} \mathrm{AI}$ or natural mating scheme is faster in dissemination of genes to 
Table 4. The effect of the number of matings per cow with 8 selected sires when the number of dams is varied for the multiple-ovulation embryo transfer (MOET) nucleus scheme (MNS).

\begin{tabular}{|c|c|c|c|c|c|c|c|c|}
\hline \multirow{2}{*}{$\begin{array}{l}\text { Dams } \\
\text { selected }\end{array}$} & \multirow[b]{2}{*}{ Matings $^{1}$} & \multirow{2}{*}{$\begin{array}{l}\text { Cows } \\
\text { tested }\end{array}$} & \multicolumn{2}{|c|}{$\operatorname{Dams}^{2}$} & \multicolumn{2}{|c|}{ Sires $^{2}$} & \multirow[b]{2}{*}{$\mathrm{G}\left(\sigma_{\mathrm{p}}\right)^{3}$} & \multirow[b]{2}{*}{$\mathrm{F}^{4}$} \\
\hline & & & $r_{I H}$ & i & $\mathrm{r}_{\mathrm{IH}}$ & i & & \\
\hline \multicolumn{9}{|l|}{64} \\
\hline & 1 & 128 & 0.58 & 0.798 & 0.44 & 1.647 & 0.230 & 0.018 \\
\hline & 2 & 256 & 0.62 & 1.271 & 0.51 & 1.647 & 0.324 & 0.018 \\
\hline & 4 & 512 & 0.65 & 1.647 & 0.56 & 1.647 & 0.402 & 0.018 \\
\hline \multicolumn{9}{|l|}{32} \\
\hline & 2 & $\begin{array}{r}04 \\
128\end{array}$ & 0.60 & 1.271 & $\begin{array}{l}0.40 \\
0.48\end{array}$ & 1.271 & $\begin{array}{l}0.191 \\
0.279\end{array}$ & $\begin{array}{l}0.020 \\
0.020\end{array}$ \\
\hline & 4 & 128 & 0.65 & 1.647 & 0.55 & 1.271 & 0.364 & 0.020 \\
\hline 16 & 1 & 32 & 0.55 & 0.798 & 0.36 & 0.798 & 0.149 & 0.023 \\
\hline & 2 & 64 & 0.59 & 1.271 & 0.45 & 0.798 & 0.233 & 0.023 \\
\hline & 0.010 & 128 & 0.64 & 1.647 & 0.53 & 0.798 & 0.313 & 0.023 \\
\hline & 1 & 16 & 0.55 & 0.798 & 0.35 & 0.000 & 0.100 & 0.031 \\
\hline & 2 & 32 & 0.58 & 1.271 & 0.43 & 0.000 & 0.168 & 0.031 \\
\hline & 4 & 32 & 0.63 & 1.647 & 0.51 & 0.000 & 0.237 & 0.031 \\
\hline
\end{tabular}

${ }^{1}$ The base schemes are those with 2 matings.

${ }^{2} \mathrm{r}_{\mathrm{IH}}=$ Accuracy of selection, $\mathrm{i}$ = selection intensity; $\mathrm{r}_{\mathrm{IH}}$ and $\mathrm{i}$ were different for dams and sires.

${ }^{3} \mathrm{G}=$ Rate of genetic gain measured in phenotypic standard deviations $\left(\sigma_{\mathrm{p}}\right)$.

${ }^{4} \mathrm{~F}=$ Rate of inbreeding.

the commercial population. When selection pathways are compared, the continuous MOET $\mathrm{F}_{1}$ production scheme had higher CDES for the SS and DS paths but lower CDES for the $\mathrm{SD}$ and $\mathrm{DD}$ paths than the $\mathrm{F}_{2}$ scheme. This is because for these paths it takes a shorter time for the genes to be expressed in the continuous MOET $F_{1}$ production scheme. The CDES at $0 \%$ interest rate for the SS and DS selection paths were similar in continuous MOET $\mathrm{F}_{1}$ production and $\mathrm{F}_{1} \mathrm{AI}$ or natural mating schemes.

\section{DISCUSSION}

The aim of this study was to compare MNS and CNS in terms of annual genetic gains, which depend on selection intensity, accuracy of selection, genetic standard deviations, generation interval, inbreeding rates per generation, and cumulative revenues. For this purpose, the structures of the schemes simulated in this study were relatively simple and within the herd, and discrete generations of selection were followed with animals eligible

Table 5. The effect of the number of selected sires when the number of dams is varied for the conventional progeny-testing nucleus schemes (CNS).

\begin{tabular}{|c|c|c|c|c|c|c|c|c|}
\hline \multirow{2}{*}{$\begin{array}{l}\text { Dams } \\
\text { selected }\end{array}$} & \multirow{2}{*}{$\begin{array}{l}\text { Sires } \\
\text { selected }^{1}\end{array}$} & \multirow{2}{*}{$\begin{array}{l}\text { Cows } \\
\text { tested }\end{array}$} & \multicolumn{3}{|c|}{$3.5 \mathrm{yr}^{2}$} & \multicolumn{3}{|c|}{$6.5 \mathrm{yr}^{2}$} \\
\hline & & & $\mathrm{i}^{2}$ & $\mathrm{r}_{\mathrm{IH}}$ & $\mathrm{G}\left(\sigma_{\mathrm{p}}\right)$ & $\mathrm{r}_{\mathrm{IH}}$ & $\mathbf{G}\left(\sigma_{\mathrm{p}}\right)$ & $\mathrm{F}^{3}$ \\
\hline \multicolumn{9}{|l|}{64} \\
\hline & 2 & 832 & 2.251 & 0.41 & 0.181 & 0.69 & 0.115 & 0.064 \\
\hline & 4 & 832 & 1.967 & 0.35 & 0.135 & 0.68 & 0.099 & 0.033 \\
\hline & 8 & 832 & 1.647 & 0.29 & 0.094 & 0.67 & 0.081 & 0.018 \\
\hline & 16 & 832 & 1.271 & 0.22 & 0.055 & 0.66 & 0.062 & 0.010 \\
\hline \multirow{2}{*}{\multicolumn{9}{|c|}{32}} \\
\hline & & & & & & & & \\
\hline & 2 & 416 & 1.647 & 0.35 & 0.135 & 0.68 & 0.099 & 0.066 \\
\hline & 4 & 416 & 1.271 & 0.29 & 0.093 & 0.67 & 0.081 & 0.035 \\
\hline \multirow{2}{*}{\multicolumn{9}{|c|}{16}} \\
\hline & & & & & & & & \\
\hline & 2 & 208 & 1.647 & 0.29 & 0.093 & 0.67 & 0.081 & 0.070 \\
\hline & 4 & 208 & 1.271 & 0.22 & 0.055 & 0.66 & 0.062 & 0.039 \\
\hline & 8 & 208 & 0.798 & 0.16 & 0.025 & 0.66 & 0.039 & 0.023 \\
\hline
\end{tabular}

\footnotetext{
${ }^{1}$ The base schemes are those with 8 sires selected.

${ }^{2} \mathrm{r}_{\mathrm{IH}}=$ Accuracy of selection, $\mathrm{i}=$ selection intensity, $\mathrm{G}=$ rate of genetic gain measured in phenotypic standard deviations $\left(\sigma_{\mathrm{p}}\right)$. The $\mathrm{i}$ and $\mathrm{F}$ were the same for both ages of selection.

${ }^{3} \mathrm{~F}=$ Rate of inbreeding.
} 
for selection only once. In practice, overlapping generations, in which both younger and older animals are eligible for selection, would exist. However, additional resources would be needed to retain older animals in addition to the younger animals (Ruane and Thompson, 1991). Therefore, the annual genetic gains presented in this paper are considered upper bounds, which can serve to rank the schemes and show that with a small number of animals, progress can be made even in PT schemes.

\section{Annual Genetic Gains}

Selection of dams was only practiced in the MNS and not in the CNS. In the MNS, the intensity of dam selection was the same for all sire numbers, test capacities, and number of matings and was not influenced by the number of selected dams (Tables 2 to 5). Expansion of test capacity had a positive effect on annual genetic response. As the number of dams and hence the size of the scheme increased, the overall response increased, agreeing with the findings of Ruane and Thompson (1991). This was associated with increases in accuracies of selection for both sires and dams, and male selection intensities. For example, the MNS with $64 \mathrm{dams}$ and 16 offspring per dam per year resulted in 1.53 higher genetic gain per year compared with 4 offspring (Table 3 ). A test capacity of 2 vs. 8 offspring per dam per year had the same effect as 1 vs. 4 matings per dam per year in the MNS (Table 4). With more offspring tested per dam per year, a greater number of animals were available for selection, therefore allowing more intense selection of dams and providing a greater amount of information for selection of candidates in both schemes. A test capacity of 1 offspring per dam per year had a female selection intensity of zero, because all animals were needed for replacement. This therefore may not be a good scheme. For a scheme with a given number of dams, test capacity did not influence the selection intensity of males. However, decrease in the number of dams in the scheme lowered the selection intensity of sires.

The results in the present study showed that substantial genetic gain within a breed could be made with a relatively small number of animals under pedigree and performance recording. Nicholas and Smith (1983) argued that because of the relatively small number of animals involved in a nucleus, a greater control over recording, breeding, and selection should be possible, thus leading to a larger proportion of the possible genetic gains being realized in MNS in practice. A major advantage of a MOET dairy herd is that the whole selection program would be under the control of a small number of like-minded people, in contrast to conventional progenytesting, which requires large numbers of often independently minded people to work toward the same goal in
Table 6. Cumulative discounted expressions for the different breeding schemes.

\begin{tabular}{llll}
\hline & $\begin{array}{l}\text { Selection } \\
\text { sathway }\end{array}$ & \multicolumn{2}{c}{ Interest rates } \\
\cline { 3 - 4 } Scheme & SS and DS & 0.402 & $10 \%$ \\
\hline $\mathrm{F}_{1}$ AI or natural mating & SD and DD & 0.576 & 0.054 \\
& SS and DS & 0.402 & 0.048 \\
$\mathrm{~F}_{1}$ MOET & SD and DD & 0.233 & 0.022 \\
& SS and DS & 0.323 & 0.033 \\
$\mathrm{~F}_{2}$ & SD and DD & 0.353 & 0.046 \\
\hline
\end{tabular}

${ }^{1} \mathrm{SS}=$ Sires to breed sires, $\mathrm{SD}=$ sires to breed dams, $\mathrm{DS}=$ dams to breed sires, $\mathrm{DD}=$ dams to breed dams.

a consistent and conscientious manner. Thus, a MOET dairy herd would be more likely to achieve its predicted genetic improvement than a large-scale PT program. Disease risk to a single nucleus and reliance on a single breeding unit for national improvement are the 2 main disadvantages of an MNS (Nicholas, 1996). The first could be overcome by holding different age groups of the MNS at different locations, and the second by relying on international competition, or a competition among MOET units within a country.

\section{Animal Numbers}

As demonstrated in this study, the MOET technique can offer opportunities for faster genetic gain within an indigenous breed. Therefore, MOET and related techniques such as in vitro fertilization would be most useful in obtaining cows of high genetic or economic value from nuclear herds. In the present study, the logistics of integrating the MNS into a large-scale breeding plan for continuous production of crossbred animals have been described. The number of $F_{1}$ dams needed to yield firstcalving $\mathrm{F}_{2}$ inter se heifers under $\mathrm{AI}$ or natural mating required for both pure- and crossbreeding is very large. This number would be even larger with lower reproductive rates. Consequently, the $\mathrm{F}_{1}$ production scheme may not be feasible in developing conditions given the production costs that may arise from keeping such a large population of animals. A crossbreeding study in Kenya by Kahi et al. (2000a) showed that $\mathrm{F}_{1}$ cows were closely rivaled by the rotational and the inter se crosses. The disadvantage of $F_{1}$ was particularly marked in a production system that required replacements to be raised within the system. Therefore, the general recommendation that the first cross is best suited for milk production in the tropics needs to be revisited. This recommendation has been based on comparisons of different breed proportions in static crossbreeding systems without due regard to the overall production system (Kahi et al., 2000a). The current study indicated that, despite the CDES being 
not as high for schemes using inter se mating, they are logistically attractive because they produce their own replacements and the number of purebred indigenous females required would be easy to attain.

Calculations in this study show that for natural service, the number of bulls needed would be very high to be attained from a nucleus scheme. Consequently, a nucleus bull scheme is only viable under AI conditions and may not be practical, at least in the short run, in extensive breeding programs under natural mating. One alternative in the use of natural mating is the creation of bull centers within reasonable distances where farmers can take their cows for mating (Swai, 1991; Kahi et al., 2004). The success of such an arrangement depends on economics, disease control measures, the recognition and appreciation of superior bulls, and the willingness of farmers to use them. Assuming an MNS producing 4 male offspring per dam per year, it would be easy to get the 10 bulls needed for AI. Conversely, the number of dams to produce 5000 bulls per year for natural service would have to be 1250 , which may not be feasible under developing conditions.

\section{Contribution of a MOET Nucleus Scheme}

The rate of genetic gain in the nucleus is twice that in $\mathrm{F}_{1}$ animals, because nucleus females contribute only $50 \%$ of the genes to the crosses. Because it is expected that the nucleus has a higher genetic level than the lower tiers, the time lag in the passage of genes from selected animals in the nucleus to the next generation in the $F_{1}$ commercial female population is longer than that between the $\mathrm{F}_{1}$ males and commercial female population. The $\mathrm{F}_{2}$ cows are expected to genetically lag behind $\mathrm{F}_{1}$ males, because the latter are used as parents of the $\mathrm{F}_{2}$ cows. It is therefore evident that MOET reduces genetic lag between the nucleus and commercial population. This may make MNS preferable in breeding programs involving production of crossbred dairy cattle.

The importance of recording animal performance and using these records in animal breeding cannot be overemphasized. Routine large scale milk and pedigree recording is not a common feature in developing countries for various reasons: lack of funds to execute a milk recording scheme; small herd size, which makes regular testing difficult to organize; poor infrastructure, e.g., roads, communication network, and farmers' organizations; lack of incentives for farmers to record data; no appreciation of the value of progeny-tested sires; poor facilities for collecting and processing data, and lack of qualified extension workers and recorders (Kahi et al., 2004). These problems could largely, be solved by adopting a MOET nucleus scheme. The expense of MOET is frequently prohibitive in developing countries due to the
Table 7. Cumulative discounted revenues (US\$) for schemes with 64 dams after $30 \mathrm{yr}$ of one round of selection.

\begin{tabular}{lllr}
\hline \multirow{2}{*}{ Scheme } & Selection & \multicolumn{2}{c}{ Interest rates } \\
\cline { 3 - 4 } pathway $^{1}$ & $0 \%$ & $10 \%$ \\
\hline$F_{1}$ AI or natural mating & SS & 20.30 & 2.70 \\
& SD & 29.00 & 5.40 \\
& DS & 19.00 & 2.60 \\
& DD & 27.20 & 5.10 \\
$F_{1}$ MOET & Total & 95.50 & 15.80 \\
& SS & 20.30 & 2.40 \\
& SD & 11.75 & 1.10 \\
& DS & 19.00 & 2.30 \\
$\mathrm{~F}_{2}$ & DD & 11.00 & 1.10 \\
& Total & 62.05 & 6.90 \\
& SS & 16.30 & 1.70 \\
& SD & 17.80 & 2.30 \\
& DS & 15.30 & 1.55 \\
& DD & 16.70 & 2.20 \\
& Total & 66.10 & 7.75 \\
\hline
\end{tabular}

${ }^{1} \mathrm{SS}=$ Sires to breed sires, $\mathrm{SD}=$ sires to breed dams, $\mathrm{DS}=$ dams to breed sires, $\mathrm{DD}=$ dams to breed dams.

required importation of inputs (Seidel and Seidel, 1992). However, the centralization of facilities optimizes the use of the scarce human, financial, and physical resources. A MOET scheme reduces the generation intervals and the genetic lag between the nucleus and commercial population. It increases the reproductive ability of the females, and consequently the number of candidates for selection in the nucleus with increased accuracy of selection. These benefits may eventually make MOET nucleus schemes preferable in breeding programs involving production of crossbred dairy cattle.

\section{CONCLUSIONS}

Crossbred cattle contribute significantly to dairy production in the tropics and are more adapted to poor environmental and management conditions than the purebred imported genotypes. It is evident that substantial genetic gain within a breed can be made with a relatively small number of animals under pedigree and performance recording. Nucleus schemes can therefore be used to capitalize on embryo transfer technology. The centralization of facilities optimizes the use of the scarce human, financial, and physical resources. The success of continuous crossbreeding schemes should focus on the logistics of applying the nucleus schemes. The large number of $B$. indicus animals that need to be involved in continuous $F_{1}$ production is a major drawback to the scheme, notwithstanding the high heterosis effect of the $\mathrm{F}_{1}$ animals. Despite the CDES being not as high for schemes using inter se mating, they are logistically attractive because they produce their own replacements and the number of purebred indigenous females required 
would be easy to attain. The main problem with the use of high technology in developing countries is their lack of experience and facilities for such developments. Therefore, technical and financial constraints of nucleus schemes and their implementation should be addressed before any move is made toward their application.

\section{ACKNOWLEDGMENTS}

The sponsorship of the World Bank through the Government of the Republic of Kenya and of the German Academic Exchange Service (DAAD, Bonn, Germany) of the first and second author, respectively, is gratefully acknowledged. We are grateful to Liesbeth van der Waaij and Anna-Elisa Liinamo, for their helpful suggestions on the draft of the paper. This paper was written when I. S. Kosgey and A. K. Kahi were at the Animal Breeding and Genetics Group, Wageningen University, the Netherlands.

\section{REFERENCES}

Brascamp, E. W. 1978. Methods on economic optimization of animal breeding plans. Rapport B-134, Instituut voor Veeteeltkundig Onderzoek 'Schoonoord,' Zeist, The Netherlands.

Callesen, H., T. Liboriussen, and T. Greve. 1996. Practical aspects of multiple ovulation-embryo transfer in cattle. Anim. Reprod. Sci. 42:215-226.

Cunningham, E. P. 1989. Formulation of breeding plans for dairy and dual-purpose cattle. Brazil. J. Genet. 12:81.

Cunningham, E. P., and O. Syrstad. 1987. Crossbreeding Bos indicus and Bos taurus for milk production in the tropics. Anim. Prod. Health Paper No. 68. FAO, Rome, Italy.

de Boer, I. J. M., and J. A. M. van Arendonk. 1994. Additive response to selection adjusted for effects of inbreeding in a closed dairy cattle nucleus assuming a large number of gametes per female. Anim. Prod. 58:173-180.

de Vaccaro, L. 1990. Survival of European dairy breeds and their crosses with Zebus in the tropics. Anim. Breed. Abstr. 58:475-494.

Elsen, J. M. 1980. Diffussion du progrès génétique dans les populations avec générations imbriquées: Quelques propriétés d'un modèle de prévision. Ann. Genet. Sel. Anim. 12:49-80.

Franklin, I. R. 1986. Breeding ruminants for the tropics. Proc. 3rd World Congr. Genet. Appl. Livest. Prod., Lincoln, NE. 11:451-461.

Groen, A. F. 1990. Influences of production circumstances on the economic revenue of cattle breeding programmes. Anim. Prod. $51: 469-480$.

Hazel, L. N. 1943. The genetic basis for constructing selection indexes. Genetics 28:476-490.

Hill, W. G. 1974. Prediction and evaluation of response to selection with overlapping generations. Anim. Prod. 18:117-139.

Hodges, J. 1990. Genetic improvement of livestock in developing countries using the open nucleus breeding system. Pages 13-22 in Proc. FAO Conf. Open Nucleus Breeding Systems, Bialobrzegi, Poland. Polish Scientific Publishers, Warsaw, Poland.

Kahi, A. K., G. Nitter, W. Thorpe, and C. F. Gall. 2000a. Crossbreeding for dairy production in the lowland tropics of Kenya. II. Prediction of performance of alternative crossbreeding strategies. Livest. Prod. Sci. 63:55-63.

Kahi, A. K., W. Thorpe, G. Nitter, J. A. M. van Arendonk, and C. F. Gall. 2000b. Economic evaluation of crossbreeding for dairy production in a pasture-based production system in Kenya. Livest. Prod. Sci. 65:167-184.

Kahi, A. K., and G. Nitter. 2004. Developing breeding schemes for pasture-based dairy production systems in Kenya. I. Derivation of economic values using profit functions. Livest. Prod. Sci. 88:161-177.

Kahi, A. K., G. Nitter, and C. F. Gall. 2004. Developing breeding schemes for pasture based dairy production systems in Kenya. II. Evaluation of alternative objectives and schemes using a two-tier open nucleus and the young bull system. Livest. Prod. Sci. 88:179-192.

Kosgey, I. S. 1997. Potential benefit and implementation of nucleus breeding scheme for milk production from crossbred cattle in Kenya. M.Sc. Thesis. Wageningen Agric. Univ., Wageningen, the Netherlands.

Lindström, U. B. 1976. Milk recording in developing countries. World Anim. Rev. 19:34-42.

Madalena, F. E. 1993. A simple scheme to utilize heterosis in tropical dairy cattle. World Anim. Rev. 74/75:17-25.

McGuirk, B. 1992. MOET Dairy cattle breeding projects-Their potential relevance to developing countries. Page 110 in Proc. Anim. Reprod. Breed. Part 1. Potentials and limitations of biotechnology in livestock production in developing countries. Mariensee, Germany. Council for Tropical and Subtropical Agricultural Research (ATSAF), Stuttgart, Germany.

Mpofu, N., C. Smith, and E. B. Burnside. 1993. Breeding strategies for genetic improvement of dairy cattle in Zimbabwe. 1. Genetic evaluation. J. Dairy Sci. 76:1163-1172.

Nicholas, F. W. 1996. Genetic improvement through reproductive technology. Anim. Reprod. Sci. 42:205-214.

Nicholas, F. W., and C. Smith. 1983. Increased rates of genetic change in dairy cattle by embryo transfer and splitting. Anim. Prod. 36:341-353.

Rendel, J. M., and A. Robertson. 1950. Estimation of genetic gain in milk yield by selection in a closed herd of dairy cattle. J. Genet. $50: 1-8$.

Ruane, J., and R. Thompson. 1991. Comparison of simulated theoretical results in adult MOET nucleus schemes for dairy cattle. Livest. Prod. Sci. 28:1-20.

Seidel, G. E., Jr., and S. M. Seidel. 1992. Analysis of application of embryo transfer in developing countries. Page 68 in Proc. Anim. Reprod. Breed. Part 1. Potentials and limitations of biotechnology in livestock production in developing countries. Mariensee, Germany. Council for Tropical and Subtropical Agricultural Research (ATSAF), Stuttgart, Germany.

Smith, C. 1988. Genetic improvement of livestock, using nucleus breeding units. World Anim. Rev. 65:2-10.

Swai, E. S. 1991. The role of village bull centres in dairy cattle, experiences of East Northern Highland of Tanga Region. Livest. Newsl. 2:13-15.

Syrstad, O. 1989. Dairy cattle cross-breeding in the tropics: Performance of secondary cross-bred populations. Livest. Prod. Sci. 23:97-106.

Teodoro, R. L., F. E. Madalena, and C. Smith. 1996. The value of $F_{1}$ dairy Bos taurus-Bos indicus embryos for milk production in poor environments. J. Anim. Breed. Genet. 113:471-481.

Verneque, R. D. S., J. C. Milagres, M. D. A. Silva, and E. A. Ludwig. 1987. Parâmetros genéticos e fenotípicos de características productivas de um rebanho gir leiteiro. Rev. Soc. Bras. Zoot. 16:222226. (In Portuguese) 